International Journal of Social Sciences and Humanities
Available online at http://sciencescholar.us/journal/index.php/ijssh
Vol. 1 No. 1, April 2017, pages: 27 38
e-ISSN : 2550-7001, p-ISSN : 2550-701X
http://dx.doi.org/10.21744/ijssh.v1i1.13

\title{
A Study on the Selection Criteria of Different Hotels of Delhi NCR in Accordance to the HR Policies and Market Trends
}

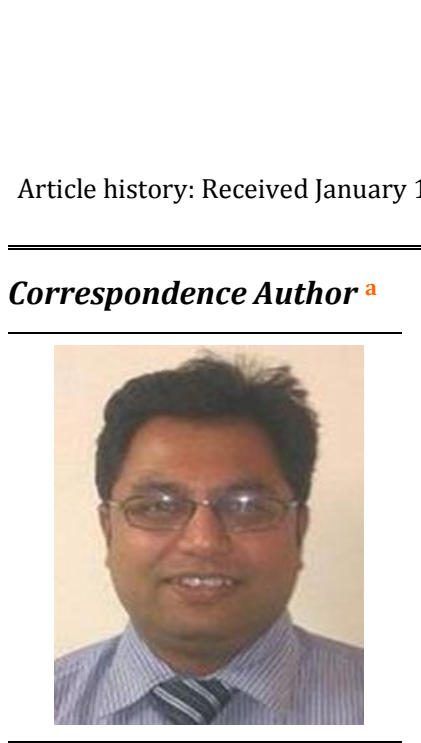

Keywords

Policies attributes;

Recruitment;

Selection criteria;

Soft skills commitment;

Sustainability;
Ayan Basak a; Kavita Khanna ${ }^{\text {b; }}$

17; Accepted in revised form February
Available online February 19, 2017 
challenges the human resource department to fill the vacant position with the right candidate that keeps on changing with the skills, attributes, experience, and education required performing a particular job. Selection consists of having an insight to select a right person, whereas the staffing consists of determining the staff strength based upon productivity standard. Selection procedure not only constrained to judging the knowledge but also comprises assessments of several soft skills like communication, attitude, assertiveness, team dynamics, leadership skill, problem solving tactics and overall personality of the candidate, that's why fixing of selection criteria holds so much of importance in the process of selection. In the process of selecting the right candidate, some other attributes are also examined for the loyalty and sustainability of employees like commitment, flexibility, quality, ability to work in a team and so on. The research location chosen for this paper is various luxury hotels and premium restaurants in Delhi NCR. The focus was to check the strategies adopted by HR department for selection of employees. These strategies have been evolved over a period of time after studying the recruitment policies, employment source and trend in the market. The method chosen for research is a questionnaire, which was duly filled by the Training managers, HR managers, and operational heads. These responses have been the guiding tools to gauge the employability skills of the candidate and to formulate selection criteria to hand pick the best from the rest.

e-ISSN : 2550-7001, p-ISSN : 2550-701X@ Copyright 2017. The Author. SS Journals Published by Universidad Técnica de Manabí.

This is an open-access article under the CC BY-SA 4.0 license

(https://creativecommons.org/licenses/by-sa/4.0/) All rights reserved.

\section{Contents}

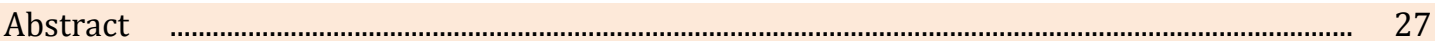

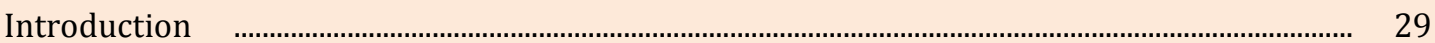

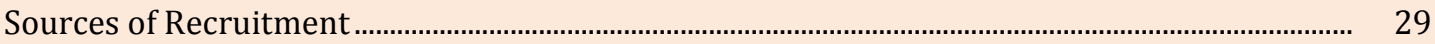

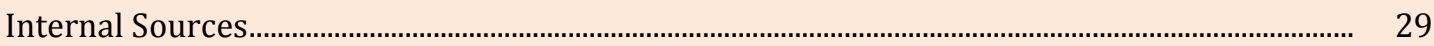

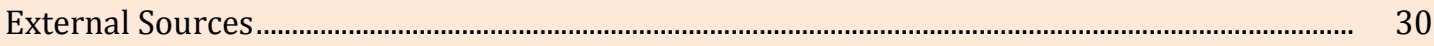

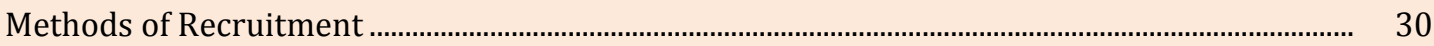

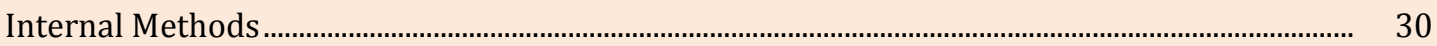

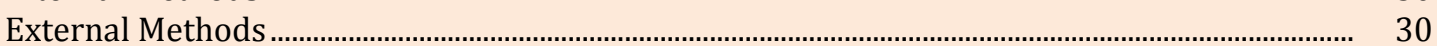

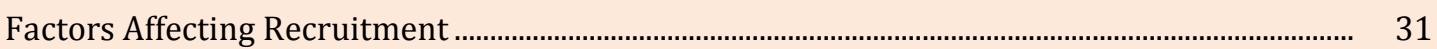

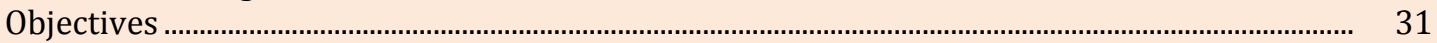

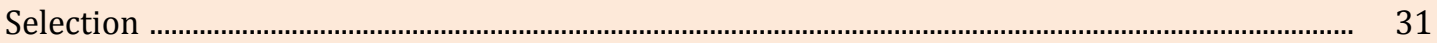

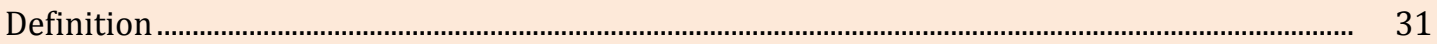

Selection Procedure of Hotel Management across Delhi-NCR Region ............................................. 31

An Inside View of Recruiters Regarding the Selection Criteria Set Up By Them While

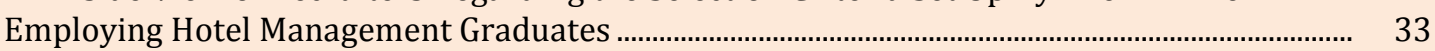

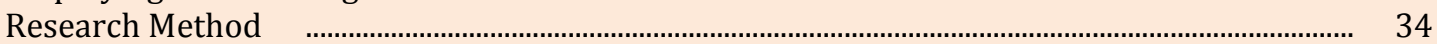

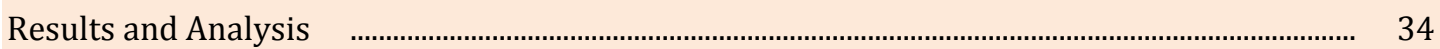

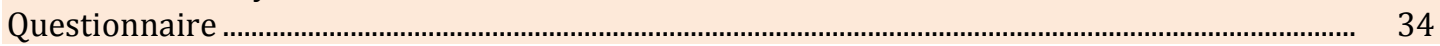




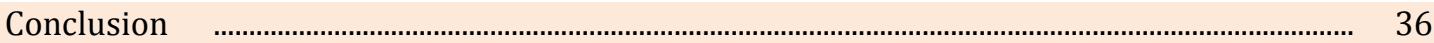

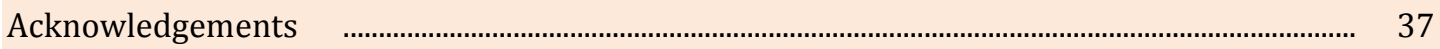

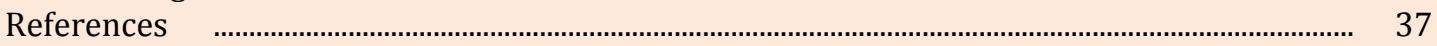

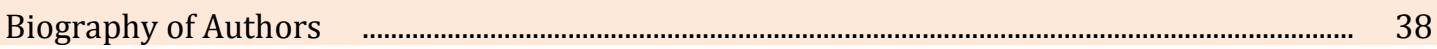

\section{Introduction}

The role of Human Resources is changing as fast as technology and the global marketplace. Historically, the HR Department was viewed as administrative overhead. HR processed payroll, handled benefits administration, kept personnel files, and other records managed the hiring process and provided other administrative support to the business. Those times have changed. Now HR professionals have the opportunity to play a more strategic role in the business. The challenge for HR managers is to keep up to date with the latest HR innovations - technological, legal, and otherwise.

Human resource is an important corporate asset and the overall performance of the company depends on the way it is put to use. In order to realize company objectives, it is essential to recruit people with requisite skills, qualification, and experience. While doing so we need to keep present and future requirements of the company in mind. Successful recruitment methods include a thorough analysis of the job and the labor market conditions. Staffing is almost central to any management process and failure in this process can create difficulties for any company including an adverse effect on its profitability and inappropriate levels of staffing or skills. Inadequate recruitment can lead to labor shortages or problems in management decision making. Staffing is however not just a simple selection process but also requires management decision making and extensive planning to employ the most suitable manpower. Competition among business organizations for recruiting the best potential has increased focus on innovation, and management decision making and the selectors aim to recruit only the best candidates who would suit the corporate culture, ethics, and climate specific to the organization. The process of recruitment does not, however, end with application and selection of the right people but involves maintaining and retaining the employees chosen.

Hospitality is a $24 X 7$ industry with tremendous scope for well skilled human resources. The hospitality industry in India is experiencing good business, better than ever before. Hotels across all segments are reporting strong occupancies and average rate. A buoyant domestic economy, the aviation, real estate boom, initiatives to liberalize foreign investment and improved infrastructure and perhaps most importantly efforts to communicate the BRAND INDIA message have contributed to strong demand conditions in most cities across the country, with the result that India is, today one of the world's fastest growing market.

RECRUITMENT: - Recruitment is defined as, "a process to discover the sources of manpower to meet the requirements of the staffing schedule and to employ effective measures for attracting that manpower in adequate numbers to facilitate effective selection of an efficient workforce."

Edwin B. Flippo defined recruitment as "the process of searching for prospective employees and stimulating them to apply for jobs in the organization." In simple words, recruitment can be defined as a 'linking function'-joining together those with jobs to fill and those seeking jobs.

\section{Sources of Recruitment}

The sources of recruitment may be broadly divided into two categories: internal sources and external sources. Both have their own merits and demerits.

\section{Internal Sources}

Persons who are already working in an organization constitute the 'internal sources'. Retrenched employees, retired employees, dependents of deceased employees may also constitute the internal sources. Whenever any vacancy arises, someone from within the organization is upgraded, transferred, promoted or even demoted.

Basak, A., \& Khanna, K. (2017). A study on the selection criteria of different hotels of Delhi NCR in accordance to the hr policies and market trends. International Journal of Social Sciences and Humanities, 1(1), 27-38. https://doi.org/10.29332/ijssh.v1n1.13 


\section{External Sources}

External sources lie outside an organization. Here the organization can have the services of: (a) Employees working in other organizations; (b) Jobs aspirants registered with employment exchanges; (c) Students from reputed educational institutions; (d) Candidates referred by unions, friends, relatives and existing employees; (e) Candidates forwarded by search firms and contractors; (f) Candidates responding to the advertisements, issued by the organization; and (g) Unsolicited applications/ walk-ins.

\section{Methods of Recruitment Internal Methods}

1. Promotions and Transfers: - This is a method of filling vacancies from internal resources of the company to achieve optimum utilization of a staff member's skills and talents. The transfer is the permanent lateral movement of an employee from one position to another position in the same or another job class assigned to usually same salary range. Promotion, on the other hand, is the permanent movement of a staff member from a position in one job class to a position in another job class of increased responsibility or complexity of duties and in a higher salary range.

2. Job Posting: - Job Posting is an arrangement in which a firm internally posts a list of open positions (with their descriptions and requirements) so that the existing employees who wish to move to different functional areas may apply. It is also known as Job bidding. It helps the qualified employees working in the organization to scale new heights, instead of looking for better perspectives outside. It also helps the organization to retain its experienced and promising employees.

3. Employee Referrals: - It is a recruitment method in which the current employees are encouraged and rewarded for introducing suitable recruits from among the people they know. The logic behind employee referral is that "it takes one to know one". This provides a lot of benefits like- Quality Candidates, Cost savings, Faster recruitment cycles, Incentives to current employees.

\section{External Methods}

1. Direct External Recruitment Methods/ Campus Recruitment: -In Campus Recruitment, Companies / Corporate visit some of the most important Technical and Professional Institutes in an attempt to hire young intelligent and smart students at the source. It is common practice for Institutes today to hire a Placement Officer who coordinates with small, medium and large sized Companies and helps in streamlining the entire Campus Recruitment procedure. This provides a lot of benefits like- Companies get the opportunity to choose from and select the best talent in a short span of time, Companies end up saving a lot of time and efforts that go in advertising vacancies, screening and eventually selecting applicants for employment and college students who are just passing out get the opportunity to present themselves to some of the best companies within their industry of interest. Landing a job offer while still in college and joining just after graduating is definitely what all students dream of. On the negative front, campus recruiting means hiring people with little or no work experience.

\section{Indirect External Recruitment Methods}

a. Advertisements: - Advertisements are the most common form of external recruitment. They can be found in many places (local and national newspapers, notice boards, recruitment fairs) and should include some important information relating to the job (job title, pay package, location, job description, how to apply either by CV or application form, etc). Where a business chooses to advertise will depend on the cost of advertising and the coverage needed i.e. how far away people will consider applying for the job. 
b. Walk-ins: - Walk-ins is relatively inexpensive, and applicants may be filed and processed whenever vacancies occur. Walk-in provide an excellent public relations opportunity because well-treated applicants are likely to inform others. On the other hand, walk-ins show up randomly, and there may be no match with available openings. This is particularly true for jobs requiring specialized skills.

c. Public and private employment agencies: - Public and private employment agencies are established to match job openings with listings of job applicants. These agencies also classify and screen applicants. Most agencies administer work-sample tests, such as typing exams, to applicants.

d. E-Recruiting: - There are many methods used for e-recruitment, some of the important methods like -Job boards, Employer websites, Professional websites, Gate Hiring, and Contractors.

\section{Factors Affecting Recruitment}

The following are the important factors affecting Recruitment:

1) Internal Factors

Recruiting policy

Temporary and part-time employees

Recruitment of local citizens

Engagement of the company in HRP

Company's size

Cost of recruitment

Company's growth and expansion

2) External Factors

Supply and Demand factors

Unemployment Rate

Labour market conditions

Political and legal considerations

Social factors

Economic factors

Technological factors

\section{Objectives}

1. To study the selection criteria of different hotels in accordance with the HR policies and market trends.

2. To analyze the preference of degree/grade against attributes.

3. To know importance of soft skills, attitude and theoretical knowledge.

4. To give the valuable suggestions.

\section{Selection}

\section{Definition}

To select means to choose. Selection is the process of picking individuals who have relevant qualifications to fill jobs in an organization. The basic purpose is to choose the individual who can most successfully perform the job from the pool of qualified candidates.

\section{Selection Procedure of Hotel Management across Delhi-NCR Region}

Selection is usually a series of hurdles or steps. Each one must be successfully cleared before the applicant proceeds to the next one. The time and emphasis placed on each step will definitely vary from one organization to another and indeed, from job to job within the same organization. The sequence of steps may also vary from job to job and organization to organization. For example, some organizations may give more importance to testing while others give more emphasis to interviews and reference checks. Similarly, a single brief selection interview might

Basak, A., \& Khanna, K. (2017). A study on the selection criteria of different hotels of Delhi NCR in accordance to the hr policies and market trends. International Journal of Social Sciences and Humanities, 1(1), 27-38. https://doi.org/10.29332/ijssh.v1n1.13 
be enough for applicants for lower level positions, while applicants for managerial jobs might be interviewed by a number of people.

1. Reception: - A company is known by the people it employs. In order to attract people with talents, skills, and experience a company has to create a favorable impression on the applicants' right from the stage of reception. Whoever meets the applicant initially should be tactful and able to extend help in a friendly and courteous way. Employment possibilities must be presented honestly and clearly. If no jobs are available at that point of time, the applicant may be asked to call back the personnel department after some time.

2. Screening Interview: - A preliminary interview is generally planned by large organizations to cut the cost of selection by allowing only eligible candidates to go through the further stages in selection. A junior executive from the Personnel Department may elicit responses from the applicants on important items determining the suitability of an applicant for a job such as age, education, experience, pay expectations, attitude, location, choice etc. this 'courtesy interview' as it is often called helps the department screen out obvious misfits. If the department finds the candidate suitable, a prescribed application form is given to the applicants to fill and submit.

3. Application Blank: - Application blank or form is one of the most common methods used to collect information on the various aspects of the applicants' academic, social, demographic, work-related background and references. It is a brief history sheet of employee's background.

4. Selection Testing: - Selection tests or the employment tests are conducted to assess intelligence, abilities, and personality trait. A test is a standardized, objective measure of a person's behavior, performance or attitude. It is standardized because the way the tests is carried out, the environment in which the test is administered and the way the individual scores are calculated- are uniformly applied. It is objective in that it tries to measure individual differences in a scientific way giving very little room for individual bias and interpretation. Some of them are - Intelligence Tests, Aptitude Test, Personality Test, Simulation Tests, and Graphology Test.

4. Evaluation: Evaluation is done on basis of answers and justification given by the applicant in the interview.

5. Physical and Medical examination: After the selection decision and before the job offer is made, the candidate is required to undergo a physical fitness test. A job offer is often contingent upon the candidate being declared fit after the physical examination.

6. Reference checks: Once the interview and medical examination of the candidate are over, the personnel department will engage in checking references. Candidates are required to give the names of 2 or 3 references in their application forms. These references may be from the individuals who are familiar with the candidate's academic achievements or from the applicant's previous employer, who is well versed with the applicant's job performance and sometimes from the co-workers.

7. Hiring decision: The line manager has to make the final decision now - whether to select or reject a candidate after soliciting the required information through different techniques discussed earlier. The line manager has to take adequate care of taking the final decision because of economic, behavioral and social implications of the selection decisions. A careless decision of rejecting a candidate would impair the morale of the people and they suspect the selection procedure and the very basis of selection in a particular organization. A true understanding between line managers and personnel managers should be established so as to facilitate good selection decisions. After taking the final decision, the organization has to intimate this decision to the successful as well as unsuccessful candidates. The organization sends the appointment order to the successful candidates either immediately or after some time depending upon its time schedule.

An Inside View of Recruiters Regarding the Selection Criteria Set Up By Them While Employing Hotel Management Graduates 
In a developing country such as India where the jobless rate is $4.9 \%$ that's equals to 44.79 million unemployed persons (tradingeconomics.com, 2014), it is expected that university graduates should be able to find employment but there are many who do not (National Employability Report). The labor market oscillates between the skills shortage on one hand and the number of graduates who are without work on the other. It seems illogical that a country with a high unemployment rate, has graduates without work, and that professionals need to be lured to the country or the locals have to compromise on salary and other benefits. This situation may arise from the fact that students lack employability skills. Behavioral (soft) skills such as those gained through curricula that embed critical outcomes such as analytical skills, teamwork, organize and manage oneself, usually deliver more competent and employable graduates (Coll \& Zegwaard, 2006).

According to the National Employability Report for Hotel Management Graduates released by employability solutions firm Aspiring Minds, it was found that the percentage of hotel management candidates who are directly employable for a hospitality job after college is quite low at $6 \%$ to $18 \%$. More than 3,000 hotel management students from over 120 hotel management colleges across multiple Indian states who underwent a 2-hour Hospitality Employability Test, India's only Competency-based assessment instrument for the hospitality industry. Candidates scored low on fundamental skills like English language skill, Logical Ability and soft skills like Self-Management, Quality Orientation, and Managerial Skills etc.

According to the report, almost $19-43 \%$ of candidates are unemployable because of their lack of English Language skill, the preferred language of communication in almost all luxury hotels and premium restaurants.

The report further states that females are more hirable ( $8-32 \%$ ) as compared to males (6 $16 \%$ ) across all profiles. Even though females in hotel management colleges have better cognitive skills and behavioral competencies as compared to their male counterparts, the females vs. males ratio in Hotel Management colleges is quite low. Employability of IHMs is significantly higher than non- IHMS and yet almost $50 \%$ of the employable pool of Hotel Management candidates is invisible to recruiters.

Employability of IHMs (39-49\%) is significantly higher than that of Non-IHMs (25-31\%). Since most companies restrict themselves to visiting IHMs and few other institutes, hospitality companies miss out on almost $50 \%$ of employable candidates, i.e. around 3000 candidates who are studying in the bottom 600 percentile Hotel Management institutions.

After interacting with the recruiters mainly HR managers, Training managers, and operational heads and analyzing the questionnaire it was found that instead of the duration of the degree or the aggregate percentage scored, more weight is given on fundamental skills like English language skill, Logical Ability and soft skills like Self-Management, Quality Orientation, and Managerial Skills etc. During the initial round physical appearance or pleasant personality becomes a crucial factor in screening. Overall intelligence and assertiveness of a candidate play a major role in clearing the first hurdle towards employment. Job knowledge and trade skills are only tested in trade tests where the profile of the job is more technical. Soft skills like communication skills, leadership skills, problem-solving tactics team dynamics are given more importance over academic records. Although the duration of degree does not make any difference in the minds of recruiters but the reputation of the university and past experiences of recruitment drives does influence the selection of candidates. Here one more observation has come out that students doing masters are not given preference rather they are considered for allied departments like sales, marketing, and HR.

According to the result acquired from the questionnaire $-83 \%$ of the recruiters believe that only $20 \%$ of students are employable and this is because students are focused on acquiring bookish knowledge rather than technical hand. $76 \%$ of the recruiters stated that due to the lack of fundamental skills like English language skill, Logical Ability and soft skills like SelfManagement, Quality Orientation, and Managerial Skills 40\% of the students are tagged as unemployable. $68 \%$ of the recruiters suggested personality development and language

Basak, A., \& Khanna, K. (2017). A study on the selection criteria of different hotels of Delhi NCR in accordance to the hr policies and market trends. International Journal of Social Sciences and Humanities, 1(1), 27-38. https://doi.org/10.29332/ijssh.v1n1.13 
refinement process be a regular part of their entire curriculum. $82 \%$ of the recruiters stated that they actually look these following aspects in the candidates - soft skills like attitude, assertiveness, team dynamics, leadership skill, problem-solving tactics and overall personality of the students.

\section{Research Method}

In this paper, the data collection took place at various luxury hotels and premium restaurants in Delhi NCR region, in which the sample of more than 200 professionals (Training managers, HR managers, and operational heads) were taken. One set of questionnaire was distributed about their selection criteria during campus recruitment and the collected data was analyzed. Different tools of methodology like the Likert scale is used for the questionnaire and there are certain open-ended questions which carve out the reality of recruiters towards knowledge, attributes, and soft skill. A study of the behavior of recruiters with respect to HR Policies and Market Trends that help them to check that, during the campus recruitment drive the students are industry ready or not, which has allowed the use of following research design:

1. Sampling

2. Questionnaire Filling

3. Secondary data.

The questionnaire was highly structured, designed to be easily understood and completed in approximately five minutes, there are certain questions which are open-ended which illustrates the feelings of the recruiters before and after a recruitment drive in different campuses of Delhi NCR region.

\section{Results and Analysis Questionnaire}

\section{Recruitment Criteria Form}

Name:

I am an employee of (Organization):

Designation

Years of experience in the industry:

$\begin{aligned} & \text { Strongly Agree on } \\ & \text { Agree }\end{aligned}$
Neutral $\begin{gathered}\text { Disagree Strongly } \\ \text { Disagree }\end{gathered}$

1. In the introduction round, it is very crucial to gauge the intelligence of the candidate

2. In Group Discussion round it is very important to check how assertive the candidate is, regarding his view on the topic of discussion

3. In Technical round, utmost importance should be given to evaluating the Job knowledge and Skills of the candidate 
4. While judging the knowledge on Current Affairs it is important to check, how the candidate has planned his studies

5. Team dynamics is an important attribute for the selection of any candidate

6. Communication skill is an important attribute selection of any candidate

7. Leadership skill is an important attribute for the candidate

8. Problem solving tactics is an important attribute for the selection of any candidate

9. Marks/grades is an important criteria for the selection of any candidate

10. Physical appearance is an important criteria for the selection of any candidate

11. History or past experiences with a particular college does influence the recruitment process

12. Four year degree holders are given preference in comparison to three years

13. Post graduate candidates are given preference in comparison to graduates

14. Name of the University does influence the recruitment process

$\begin{array}{lllll}0 & 0 & 0 & 0 & 0\end{array}$

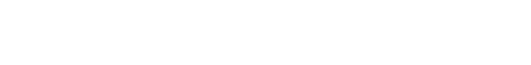

O

O

○

O

for the

selection of any

\section{Special comments}

Thank you for your participation!

Basak, A., \& Khanna, K. (2017). A study on the selection criteria of different hotels of Delhi NCR in accordance to the hr policies and market trends. International Journal of Social Sciences and Humanities, 1(1), 27-38. https://doi.org/10.29332/ijssh.v1n1.13 


\section{Conclusion}
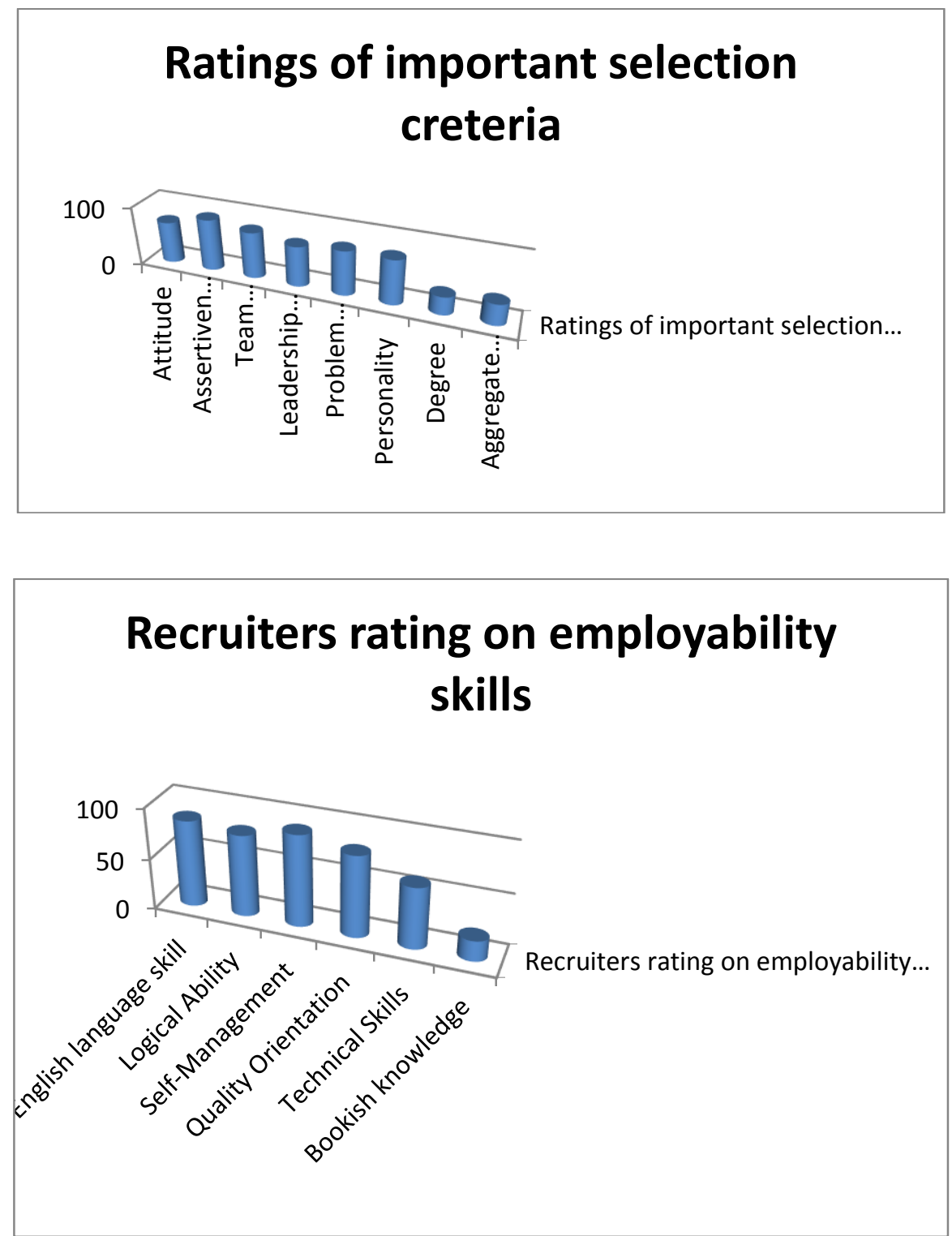


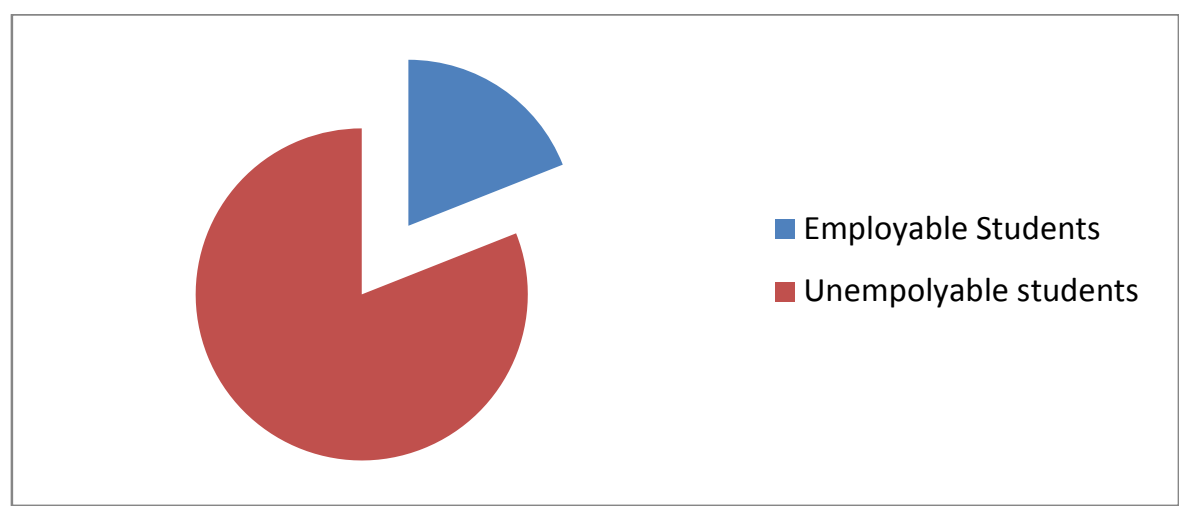

Acknowledgement

Professionals mainly Training managers, HR managers and operational heads of various luxury hotels and premium restaurants in Delhi NCR region

\section{References}

Barrie, S.C. (2006). Understanding what we mean by the generic attributes of graduates. Higher Education, 51, 215-241.

Basak, A., \& Khanna, K. (2017). A Study on the Selection Criteria of Different Hotels of Delhi NCR in Accordance to the HR Policies and Market Trends. International Journal of Social Sciences and Humanities (IJSSH), 1(1), 27-38.

Bath, D., Smith, C., Stein, C. \& Swann, R. (2004). Beyond mapping and embedding graduate attributes: bringing together quality assurance and action learning to create a validated and living curriculum. Higher Education

Billaiya, R., Malaiya, S., \& Parihar, K. S. (2017). Impact of Socio Economic Trends on Students in Quality Education System. International Journal of Social Sciences and Humanities (IJSSH), 1(1), 16-20.

Cedeño, M. L. D., Arteaga, M. G. D., Pérez, A. V., \& Arteaga, M. L. D. (2017). Regulatory Framework for Renewable Energy Sources in Ecuador Case Study Province of Manabí. International Journal of Social Sciences and Humanities (IJSSH), 1(2), 29-42.

Coll, R. \& Zegwaard, K.E. (2006). Perceptions of desirable graduate competencies for science and technology new graduates. Research in Science \& Technological Education, 24(1), 29-58.

Crebert, G., Bates, M., Bell, B., Patrick, C.J. \& Cragnolini, V. (2004). Ivory Tower to Concrete Jungle Revisited. Journal of Education and Work, 17(1), 47-70.

Fleming, J. \& Eames, C. (2005). Student Learning in Relation to the Structure of the Cooperative Experience. Asia-Pacific Journal of Cooperative Education, 6(2), 26-31.

Gámez, M. R., Pérez, A. V., Será, A. S., \& Ronquillo, Z. M. (2017). Renewable Energy Sources and Local Development. International Journal of Social Sciences and Humanities (IJSSH), 1(2), 10 19.

Gerber, R. (1998). How do workers learn in their work? The Learning organization, 5(4), 168175.

Ghosh, C. (2017). A Study on-Evaluating Marketing Strategies Adopted by Home Appliance for Economic Development in India. International Journal of Social Sciences and Humanities (IJSSH), 1(1), 9-15.

Hind, D., Moss, S. \& McKellan, S. (2007). Innovative Assessment Strategies for developing HR Practices in Hotel Industry_ Workplace Training_files. Scribd.

http://dx.doi.org/10.1080/13636820200200204, Skills, and training for the hospitality sector: a review of issues

http://lib.dr.iastate.edu/etd A review of studies on luxury hotels over the past two decades

Human Resource Practices in Hotels_ A Study from the Tourist State of Uttrakhand, India. Scribd.

Basak, A., \& Khanna, K. (2017). A study on the selection criteria of different hotels of Delhi NCR in accordance to the hr policies and market trends. International Journal of Social Sciences and

Humanities, 1(1), 27-38. https://doi.org/10.29332/ijssh.v1n1.13 
IJTD (International Journal of Training and Development)

HR Daily Advisor - BLR

\section{Biography of Authors}

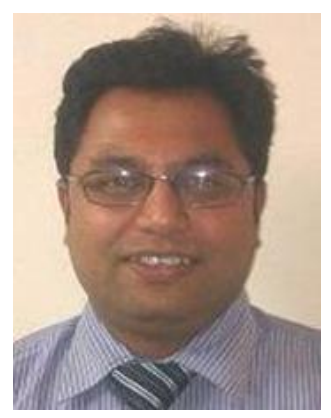

Currently working as Asst. Professor-II in Amity University, Noida. Pursuing Ph.D. (Hospitality) on "employability skills of Hospitality graduates".

NET qualified. Presented papers in different conferences and seminars

Published paper in journals, 20 years of Industrial and Educational experience in the Hospitality sector. $151 / 2$ years of qualitative experience in Hospitality Education Sector.

$2 \frac{1}{2}$ years sound and significant experience in Five Star Hotel Industry.

2 years experience of working in reputed Fast Food Sector.

Specialized in Food \& Beverage Service, Bar Management. 